\title{
THE DISTRIBUTION OF RADON CONCENTRATION IN CAVES
}

\author{
Arrigo A. CIGNA ${ }^{1}$
}

\begin{abstract}
Radon concentration in caves is known to vary within an extremely wide range. Here the distribution of the average values of radon concentration is examined and a power law describing is identified, i.e. radon concentration has a fractal dimension $\mathrm{D}=1.26$. This fact means that concentrations are not grouped around a mean value, a characteristic common to many other phenomena.
\end{abstract}

\section{Introduction}

Radon concentration in caves was measured all over the world since some decades, and a fairly large amount of data is available. The causes of variation of radon concentration are many and, often, cannot be easily identified.

In addition to the source of radon, i.e. the concentration of uranium and radium in the rock in the vicinity of the cave, earth tide, atmospheric pressure, water flow, earthquakes, etc. influence the release and distribution of radon in the cave atmosphere.

It must be emphasised that such a large number of factors is the reason why the measurement of radon concentration cannot be practically used for earthquakes forecasting, as it was thought in the past. In other words, it is possible to link the change of radon concentration to an earthquake but only after it occurred and not in advance, as it would be necessary for warning reasons.

In nature many systems display self-organised criticality. The well known Gutenberg-Richter law concerning the distribution of earthquakes correlates the frequency against the magnitude by a power law with -2 exponent; such a law was recently also generalised (Kossbokov \& Nekrasova, 2003). Other experiments carried out on the distribution of fragments resulted in a power law with -2.6 exponent (Oddershede et al., 1993). Many experiments found that a power law describes frequently a rather large number of distributions in very different fields (Turcotte, 1992).

\footnotetext{
${ }^{1}$ Frazione Tuffo, I-14023 Cocconato (Asti), Italy e-mail:arrigocigna@ tiscali.it
} 
Recently Badino (2001) reported a fractal dimension for the distribution of long caves ranging from 1.19 to 1.87 according different groups of length.

\section{Radon concentration in caves}

Already during the preparation of a paper (Cappa et al., 1995) reporting some radon measurements in Italian caves, a preliminary examination of the data available at that time suggested the absence of a mean value of the concentration. On the contrary, such values appeared to be inversely correlated with their frequency. In other words lower values were more frequent than higher values.

Hakl et al. (1995) collected 303 data from 220 different caves. They included either cave minimum and maximum data as given by authors or average values. Also these data are not grouped around a mean value but are spread over a very wide range of values. In fact it was found a lognormal distribution of the cumulative probability against radon concentration, i.e. the probability of finding a radon concentration below a given value.

Now, such data, as kindly supplied by Hakl (2004), were reported against their number occurring within each interval of $500 \mathrm{~Bq} / \mathrm{m}^{3}$ (Fig. 1). A power law, as reported in Fig. 1, gives their distribution. Such a power law means that the frequency of finding a given radon concentration decreases according a power of -1.26 , i.e. when

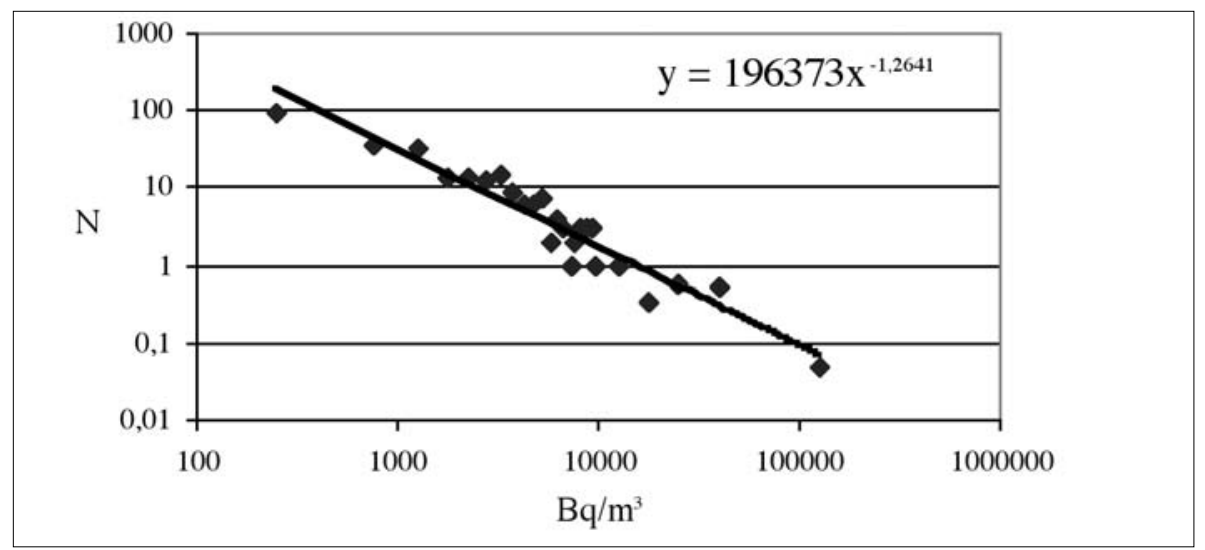

Fig. 1 - Distribution of 303 average radon concentrations from 220 caves from all over the world. Hakl (2004), within intervals of $500 \mathrm{~Bq} / \mathrm{m}^{3}$.

the value of a radon concentration is doubled the frequency decreases with a factor of about 2.4. This is equivalent to say that the fractal dimension of the radon concentration distribution is $\mathrm{D}=1.26$.

\section{Conclusion}

The examination of the distribution of 303 average radon concentrations allowed a reliable statistical treatment leading to identify a power law describing such a dis- 
tribution. The consequence of such a result is that there is not a common average value of radon concentration in caves but the values are spread over a quite large range, the higher values being less frequent than the lower values.

The chance of finding a very high radon concentration is low but not negligible, and therefore it will be very interesting to identify such high values and investigate the particular local conditions.

\section{Acknowledgements}

I express my gratitude to dr. Hakl who kindly provided the large number of radon concentration data collected from all over the world, which allowed the study reported in this note. My best thanks also to dr. G. Badino and dr. L. Tommasino for their comments.

\section{References}

BADINO G., 2001 - Has deep karst a fractal behaviour? Proc. 16 $6^{\text {th }}$ Int. Congr. of Speleology, Speleo Brazil 2001, 1:161-171.

CAPPA G., CIGNA A.A., TOMMASINO L. \& TORRI G., 1995 - Review of the radon concentration measurements in Italian caves and some aspects of radiation protection. In: Cigna A.A. (Ed.), 1996 - BOSSEA MCMXCV. Proc. "Show Caves and Environmental Monitoring" Symp. Int., Frabosa Soprana (Cuneo) 24-27-III-1995: 169-181.

HAKL J., 2004 - Personal communication to A.A.Cigna, 5 May 2004.

HAKL J., HUNYADI I. \& VÁRHEGYI A., 1995 - Radon monitoring in caves. In Durrani S.A. \& Ilic R. (Eds.) Radon measurements by etched track detectors. World Scientific: 261283.

KOSSOBOKOV V. \& NEKRASOVA A., 2003 - Generalized Gutenberg-Richter recurrence law. Geophys. Res. Abstracts, 5, 06597.

ODDERSHEDE, DIMON \& BOHR J., 1993 -Self-organized criticality in fragmenting. Phys. Rew. Letter, 71: 3107-3110.

TURCOTTE D., 1997 - Fractals and chaos in geology and geophysics. Cambridge Univ. Press. 